\title{
The chicken or the egg? The value of longitudinal research in an increasingly diverse tobacco product landscape
}

\author{
Brian A King
}

Office on Smoking and Health, Centers for Disease Control and Prevention, Atlanta, Georgia, USA

\section{Correspondence to} Dr Brian A King, Office on Smoking and Health, Centers for Disease Control and Prevention, Atlanta, GA 30333, USA; baking@cdc.gov

Check for updates

(C) Author(s) (or their employer(s)) 2020. No commercial re-use. See rights and permissions. Published by BMJ.

To cite: King BA. Tob Control 2020;29:s131-s133.
The considerable progress made in reducing cigarette smoking is among the greatest public health achievements of the past century. ${ }^{1}$ In the U.S., current cigarette smoking prevalence among adults declined from nearly 43\% in 1965 to approximately $14 \%$ in $2018 .^{23}$ Moreover, current cigarette smoking prevalence among high school students has been steadily declining since the 1998 Master Settlement Agreement, from more than 30\% in 2000 to approximately $8 \%$ in $2018 .^{45}$ However, in the U.S. and globally, the tobacco product landscape has diversified in recent years to include a variety of combustible, non-combustible, and electronic products. Approximately $70 \%$ of U.S. adults who currently use tobacco products are cigarette smokers. ${ }^{3}$ In contrast, among current tobacco product users, less than half of young adults 18-24 years old (45.6\%) and less than one-third of high school students (29.2\%) are cigarette smokers (figure 1), with an increasing proportion of youth and young adults using novel tobacco products such as e-cigarettes. ${ }^{35}$ The increasing diversification of the tobacco product landscape has implications for efforts to understand how tobacco product use changes over time, including transitions within and between product types. Longitudinal data sources are particularly useful for assessing transitions between tobacco product types. In contrast to repeated cross-sectional surveys that are traditionally used for surveillance of changes in tobacco product use at the national and subnational levels, longitudinal studies afford the ability to document the temporal order of events, thus helping to answer the proverbial question, which came first, the chicken or the egg?'.

This supplement to Tobacco Control includes 10 papers presenting a conceptional overview for, ${ }^{6}$ and analyses of, ${ }^{7-15}$ tobacco product use transitions among US youth (aged 12-17 years), young adults (aged 18-24 years) and adults aged 25 years or older using data from the first three waves (September 2013-December 2014, October 2014October 2015 and October 2015-October 2016) of the Population Assessment of Tobacco and Health (PATH) Study. In 2011, the US Food and Drug Administration (FDA) and the National Institutes of Health launched PATH to generate longitudinal epidemiological data among the US population aged 12 years and older to inform, as well as to monitor the impact of, FDA's regulatory authorities afforded under the 2009 Family Smoking Prevention and Tobacco Control Act. ${ }^{16}$ The papers in this supplement assess three broad tobacco product use transitions from PATH, including initiation of tobacco product use among non-users, cessation of tobacco product use among current users and relapse back to tobacco product use among former users. The papers also consider more complex transition patterns, including exclusive tobacco product use and the use of two or more tobacco product types (polytobacco use).

The supplement contains five papers that present data on transitions among current users of various tobacco products. Taylor et $\mathrm{al}^{7}$ assessed cigarettes, finding that smoking remained persistent across time, regardless of age, with most smokers continuing to smoke at all three waves. In contrast, Stanton et $a l^{8}$ assessed e-cigarettes, finding that use is most common among young adults than youth and adults aged 25 years or older, and that continued use of e-cigarettes over time was not common for any age group. Similarly, Sharma et $a l^{9}$ found that hookah smoking is more common among young adults than among youth or adults aged 25 years or older and that discontinuing hookah smoking is the most common pathway among exclusive or polytobacco hookah smokers. Edwards et $a l^{10}$ assessed cigars, also finding that the majority of current cigar smokers discontinued use by wave 3 ; however, adult polytobacco cigar smokers were less likely to discontinue all tobacco product use than exclusive cigar smokers. Finally, Sharma et $a l^{11}$ assessed smokeless tobacco, finding distinct transition patterns among exclusive and polytobacco smokeless tobacco users; among wave 1 exclusive smokeless tobacco users, persistent exclusive use across all three waves was more common among adults aged 25 years or older, while transitioning from exclusive smokeless tobacco use to polytobacco use at subsequent waves was more common among youth and young adults. In addition to these productspecific analyses, Stanton et $a l^{12}$ assessed transitions among never-tobacco product users, finding that across all assessed age groups, never tobacco product use decreased across waves, reflecting an overall increase in tobacco product initiation; this increase was primarily due to increased initiation of e-cigarettes among youth and young adults across waves.

The supplement also provides important insight into underlying drivers of tobacco product transition behaviours, which could help inform strategies to mitigate public health risks. Specifically, three 
All Adults ( $\geq 18$ Years)
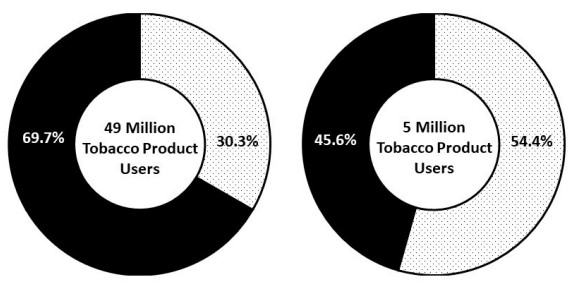

Young Adults (18-24 Years)

High School Students (Grades 9-12)

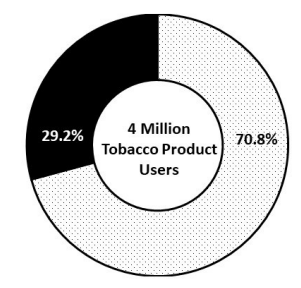

Non-Cigarette Tobacco Products

Figure 1 Current cigarette and non-cigarette tobacco product use among US adults, young adults, and high school students, 2018. Source: National Health Interview Survey (current use defined as: 'everyday' or 'someday'); National Youth Tobacco Survey (current use defined as: $\geq 1$ day in past 30 days).

papers assess correlates of the broad transition behaviours of initiation, ${ }^{13}$ cessation ${ }^{14}$ and relapse ${ }^{15}$ for each of the assessed tobacco products, including correlates of year-over-year transitions within PATH waves. Kasza $e t ~ a l^{13}$ assessed initiation, finding that ever tobacco product use and age predicted initiation across products; youth aged 15-17 years were more likely than those aged 12-14, and young adults aged 18-24 were more likely than those aged 25 years or older, to initiate current tobacco product use across assessed products. However, associations with other demographic characteristics varied by products; for example, sexual and gender minorities were more likely than heterosexuals to initiate current cigarette and e-cigarette use. Kasza et $\mathrm{al}^{14}$ assessed cessation, finding that among adult users of each tobacco product type, greater frequency of use was associated with lower likelihood of discontinuing use. Variations in demographic and tobacco behavioural correlates were also observed by product type; for example, among adult cigarette smokers, non-Hispanic whites, those with lower educational attainment and those with lower household income were less likely to discontinue cigarette smoking; e-cigarette use was positively associated with quit attempts but was not associated with quitting cigarettes, and smokeless tobacco use was positively associated with quitting cigarettes. Finally, Edwards et al ${ }^{15}$ assessed relapse, finding that any tobacco product relapse was greater among youth than adult previous users, and that shorter time since last use and greater tobacco dependence were associated with the greatest likelihood of relapse. Additionally, any tobacco product relapse was greater among male, non-Hispanic black and bisexual adults, whereas no consistent association was observed by race/ ethnicity or sexual orientation among youth. ${ }^{15}$

These findings have utility for multiple entities, including the public health practice and research communities in the USA and globally. PATH was designed with the intent of informing FDA regulatory actions. ${ }^{16}$ Thus, the findings can provide scientific evidence to support the development and evaluation of Federal rulemaking, as well as to facilitate the development of other evidence-based population-level tobacco prevention and control strategies at the international, national, state and local levels, including public education campaigns. ${ }^{17-19}$ Moreover, key correlates were identified that could inform the development of strategies focused on populations at greatest risk. For example, the increased initiation rates of e-cigarettes among youth and young adults who had previously never used tobacco products reinforces the importance of efforts to address underlying drivers of e-cigarette initiation among these populations. ${ }^{17}$ In addition to public health practice opportunities, these findings can also serve as a foundation for future

research. More specifically, PATH affords a breadth of data on a diverse array of indicators that could build on the findings from this supplement. Future work could include analysis of subsequent PATH waves that encompass use of newer generations of e-cigarettes; assessment of additional demographic correlates and tobacco use behaviours that may influence transition patterns; analysis of biomarker data in the context of self-reported tobacco product transition patterns; and exploration of subnational data to evaluate state-level policies such as flavour restrictions.

In conclusion, the tobacco control field is at the precipice of an unprecedented period in its more than 50-year history. ${ }^{1}{ }^{19}$ Commendable declines have occurred in the prevalence of cigarette smoking, which along with other combustible tobacco products are responsible for the overwhelming burden of disease and death from tobacco product use in the USA. ${ }^{19}$ However, the diversification of the tobacco product landscape has the potential for both public health promise or peril. Some novel non-combusted tobacco products, such as e-cigarettes, may help some adult combustible tobacco product users switch completely to a generally less harmful alternative. ${ }^{120}$ However, the increased initiation of e-cigarettes among never-tobacco product users, especially youth and young adults, could also subject another successive generation to nicotine addiction, including those that were not otherwise susceptible to conventional tobacco product use. ${ }^{1720}$ To provide data to inform strategies that maximise potential benefits and minimise the risks of e-cigarettes and other novel tobacco products, as well as to continue to decrease the considerable burden of combustible tobacco products, further research is needed that elucidates tobacco product trajectories and the underlying drivers of these transition behaviours. To that end, for more than a half century, longitudinal research has served a critical role in scientifically establishing factors that increase the risk of tobacco product use and tobacco-related death and disease, as well as evidence-based strategies that can prevent and reduce these risks. ${ }^{18} 19$ The PATH Study is part of the latest chapter of this legacy, and the continued analysis of data from this longitudinal cohort will be critical for assessing transitions between tobacco product types to inform the development and sustainment of strategies to prevent and reduce the health and economic burden of tobacco products use in the USA and globally.

Contributors BAK was solely responsible for the conception and writing of the reported content.

Funding The authors have not declared a specific grant for this research from any funding agency in the public, commercial or not-for-profit sectors.

Disclaimer The findings and conclusions in this report are those of authors and do not necessarily represent the official position of the US Centers for Disease Control and Prevention.

Competing interests None declared.

Patient consent for publication Not required.

Provenance and peer review Not commissioned; internally peer reviewed.

ORCID iD

Brian A King http://orcid.org/0000-0003-4175-1559

\section{REFERENCES}

1 U.S. Department of Health and Human Services. Smoking Cessation. A Report of the Surgeon General. Atlanta, GA: U.S. Department of Health and Human Services, Centers for Disease Control and Prevention, National Center for Chronic Disease Prevention and Health Promotion, Office on Smoking and Health 2020.

2 Wang TW, Asman K, Gentzke AS, et al. Tobacco Product Use Among Adults - United States, 2017. MMWR Morb Mortal Wkly Rep 2018;67:1225-32.

3 Creamer MR, Wang TW, Babb S, et al. Tobacco Product Use and Cessation Indicators Among Adults - United States, 2018. MMWR Morb Mortal Wkly Rep 2019;68:1013-9. 
4 Centers for Disease Control and Prevention. Youth tobacco surveillance - United States, 2000. Morbidity \& Mortality Weekly Report 2001;50:1036.

5 Gentzke AS, Creamer M, Cullen KA, et al. Vital Signs: Tobacco Product Use Among Middle and High School Students - United States, 2011-2018. MMWR Morb Mortal Wkly Rep 2019;68:157-64.

6 Hyland A, Kasza KA, Borek N, et al. Overview of tobacco use transitions for population health. Tob Control 2020;29:s134-8.

7 Taylor KA, Sharma E, Edwards KC, et al. Longitduinal pathways of exclusive and polytobacco use among youth, young adults, and adults in the USA: findings from the PATH Study Waves 1-3 (2013-2016). Tob Control 2020;29:s139-46.

8 Stanton CA, Sharma E, Edwards KC, et al. Longitudinal transitions of exclusive and polytobacco electronic nicotine delivery systems (ends) use among youth, young adults, and adults in the USA: findings from the PATH Study Waves 1-3 (2013-2016). Tob Control 2020;29:s147-54.

9 Sharma E, Bansal-Travers M, Edwards KC, et al. Longitudinal pathways of exclusive and polytobacco hookah use among youth, young adults, and adults in the USA: findings from the PATH Study Waves 1-3 (2013-2016). Tob Control 2020;29:s155-62.

10 Edwards KC, Sharma E, Halenar MJ, et al. Longitudinal pathways of exclusive and polytobacco cigar use among youth, young adults, and adults in the USA: findings from the PATH Study Waves 1-3 (2013-2016). Tob Control 2020;29:s163-9.

11 Sharma E, Edwards KC, Halenar MJ, et al. Longitudinal pathways of exclusive and polytobacco smokeless use among youth, young adults, and adults in the USA: findings from the PATH Study Waves 1-3 (2013-2016). Tob Control 2020;29:s170-7.

12 Stanton CA, Sharma E, Seaman EL, et al. Initiation of any tobacco and five tobacco products across 3 years among youth, young adults, and adults in the USA: findings from the PATH Study Waves 1-3 (2013-2016). Tob Control 2020;29:s178-90.
13 Kasza KA, Edwards KC, Tang Z, et al. Correlates of tobacco product initiation among youth and adults in the USA: findings from the PATH Study Waves 1-3 (2013-2016). Tob Control 2020;29:s191-202.

14 Kasza K, Edwards KC, Tang Z, et al. Correlates of tobacco product cessation among youth and adults in the United States: findings from the path study wave 1-3 (20132016). Tob Control 2020;29:s203-15.

15 Edwards KC, Kasza K, Tang Z, et al. Correlates of tobacco product reuptake and relapse among youth and adult in the USA: findings from the PATH Study Waves 1-3 (2013-2016). Tob Control 2020;29:5216-26.

16 Hyland A, Ambrose BK, Conway KP, et al. Design and methods of the population assessment of tobacco and health (path) study. Tob Control 2017;26:371-8.

17 U.S. Department of Health and Human Services. E-Cigarette use among youth and young adults. A report of the surgeon General. Atlanta, GA: U.S. department of health and human services, centers for disease control and prevention, National center for chronic disease prevention and health promotion, office on smoking and health, 2016.

18 U.S. Department of Health and Human Services. Preventing tobacco use among youth and young adults: a report of the surgeon General. Atlanta, GA: U.S.Department of Health and Human Services, Centers for Disease Control and Prevention, National Center for Chronic Disease Prevention and Health Promotion, Office on Smoking and Health, 2012.

19 U.S. Department of Health and Human Services. The health consequences of smoking: 50 years of progress. A report of the surgeon General. Atlanta, GA: U.S. Department of Health and Human Services, Centers for Disease Control and Prevention, National Center for Chronic Disease Prevention and Health Promotion, Office on Smoking and Health, 2014. Printed with corrections, 2014.

20 National Academies of Sciences, Engineering, and Medicine. Public Health Consequences of E-Cigarettes. Washington, DC: The National Academies Press, 2018. https://doi.org/ 